\title{
Trial Arms Supplemental Qualifiers Dataset
}

National Cancer Institute

\section{Source}

National Cancer Institute. Trial Arms Supplemental Qualifiers Dataset. NCI Thesaurus. Code C147254.

A dataset containing supplemental information, specifically non-standard variables, to parent records in the trial arms domain. 